CLINICAL STUDY

\title{
Interaction between heavy smoking and CYP2A6 genotypes on type 2 diabetes and its possible pathways
}

\author{
Tao Liu, Wei-Qing Chen, Sean P David ${ }^{1}$, Rachel F Tyndale ${ }^{2}$, Hui Wang, Yu-Ming Chen, Xue-Qing Yu ${ }^{3}$, Wei Chen ${ }^{3}$, \\ Qian Zhou ${ }^{2}$ and Wen-Hua Ling ${ }^{4}$ \\ Guangdong Provincial Key Laboratory of Food, Nutrition and Health, Department of Biostatistics and Epidemiology, School of Public Health, Sun Yat-Sen \\ University, 74, Zhongshan Road 2, Guangzhou, China, ${ }^{1}$ Center for Education in Family and Community Medicine, 1215 Welch Road, Modular G, \\ Stanford, California 94305, USA, ${ }^{2}$ Departments of Pharmacology and Toxicology and Psychiatry, The Center for Addiction and Mental Health, University \\ of Toronto, Toronto, Ontario, Canada M5S 1A8, ${ }^{3}$ Department of Nephrology, The First Affiliated Hospital of Sun Yat-Sen University, 58, Zhongshan Road \\ 2, Guangzhou, China and ${ }^{4}$ School of Public Health, Sun Yat-Sen University, 74, Zhongshan Road 2, Guangzhou, China \\ (Correspondence should be addressed to W-Q Chen; Email: chenwq@mail.sysu.edu.cn)
}

\begin{abstract}
Objective: To explore the interactions between smoking and CYP2A6 genotypes on type 2 diabetes (T2DM) as well as potential pathways for smoking in causing T2DM.

Design: Cross-sectional study.

Methods: A total of 1344 smokers with complete data from a community-based T2DM survey in Guangzhou and Zhuhai of China from July 2006 to June 2007 were interviewed with a structured questionnaire about socio-demographic status and daily cigarette consumption. Serum glucose, insulin, and cotinine were measured after an overnight fast. Subjects were genotyped for CYP2A6 and classified, according to genotype, into normal, intermediate, slow, or poor nicotine metabolizers based on prior knowledge of CYP2A6 allele associations with nicotine C-oxidation rate. Abdominal obesity was defined as a waist-to-hip ratio $\geq 0.90$ for males or $\geq 0.85$ for females. Type 2 diabetic patients $(n=154)$ were diagnosed according to WHO 1999 criteria. Chi-square tests, multivariate logistic regression models, and a structural equation model were used in this study.

Results: Multivariate analysis indicated that, compared with light smoking, heavy smoking significantly increased the risk of T2DM (odds ratio $(\mathrm{OR})=1.75,95 \% \mathrm{CI}=1.01-3.05$ ). There were significant interactions between heavy smoking and slow CYP2A6 $(\mathrm{OR}=5.12,95 \% \mathrm{CI}=1.08-24.23)$ and poor $C Y P 2 A 6$ metabolizer genotypes $(\mathrm{OR}=8.54,95 \% \mathrm{CI}=1.28-57.02)$ on T2DM. Structural equation modeling indicated that CYP2A6 moderation of smoking quantity risk on T2DM was mediated by the effects on serum cotinine, abdominal obesity, insulin resistance, and insulin secretion. Conclusions: Heavy smoking was significantly associated with T2DM, and this association was moderated by CYP2A6 genotype and mediated by serum cotinine, abdominal obesity, insulin resistance, and insulin secretion.
\end{abstract}

European Journal of Endocrinology $165961-967$

\section{Introduction}

There is growing evidence that cigarette smoking is an independent risk factor for type 2 diabetes (T2DM) and that a dose-response relationship between cigarettes per day and risk of T2DM exists $(1,2)$. Numerous studies suggest that smoking, and specifically nicotine, leads to abdominal obesity $(2,3)$. Moreover, smoking is associated with increased insulin resistance and decreased insulin secretion from pancreatic $\beta$-cells (3, $4)$, which in turn are associated with the development of T2DM (5). The majority of inhaled nicotine from cigarettes is metabolized into cotinine by hepatic cytochrome p450 2A6 (CYP2A6) enzymatic activity (6) and the CYP2A6 gene moderates CYP2A6 metabolic activity (7). Whether CYP2A6 genotype moderates the relationship between smoking and T2DM remains unclear. Therefore, this study aimed to explore i) whether or not CYP2A6 genotype interacts with smoking to affect risk of T2DM and ii) to examine the potential pathways underlying this relationship between smoking and T2DM.

\section{Subjects and methods}

\section{Subjects}

Subjects were from a community-based T2DM survey conducted in Guangzhou and Zhuhai, China, from July 2006 to June 2007 (8). In this survey, a four-stage sampling method was used to select a representative sample of residents in both cities. In the first stage, six administrative regions from Guangzhou and one from Zhuhai were randomly selected. In the second stage, 
one street district was randomly selected from each of the sampled seven administrative regions. In the third stage, two resident communities were randomly sampled from each selected street district. In the final stage, residents aged 20 years or older who had lived in Guangzhou or Zhuhai for not $<5$ years were invited to participate in the survey. A total of 7293 adult residents (2465 males and 4828 females) aged 20 years or older were selected. Of the 7293 sampled subjects, 1440 were smokers (1327 males and 113 females). However, 96 did not provide blood samples, resulting in a final study sample size of 1344 smokers (Fig. 1). This study was approved by the Ethics Committees of Sun Yat-sen University (Guangzhou, China) and written informed consent was obtained from all subjects.

\section{Data collection}

A face-to-face interview was conducted by trained medical students or clinical doctors using a structured questionnaire for acquiring socio-demographic characteristics of age, gender, education (illiteracy, elementary school, junior middle school, senior middle school or vocational secondary school, college, or above), smoking behavior, and other relevant information.

\section{Measurement and definition of smoking behavior}

A 'current regular smoker' was defined as a smoker who smoked more than 100 cigarettes during his lifetime and smoked at least one cigarette daily at the time of interview. A 'former smoker' was someone who had smoked more than 100 cigarettes in his lifetime but reported that he had quit smoking (9). Subjects included current and former smokers. Current and former smokers reported their average number of cigarettes consumed in the most recent period of smoking. All

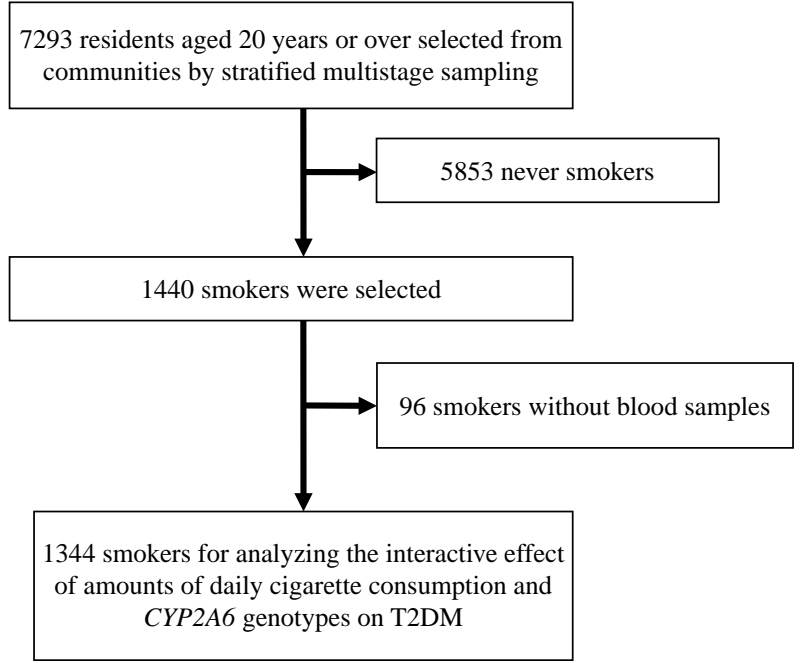

Figure 1 Study participants selection diagram. smokers were categorized into three groups according to their smoking quantity: light smoker (1-10 cigarettes per day), moderate smoker (11-20 cigarettes per day), and heavy smoker ( $>20$ cigarettes per day).

\section{Measurement and definition of alcohol consumption and physical exercise}

Alcohol consumption was defined by consumption of alcohol at least three times a week for more than 6 months (10). Physical exercise was defined by any level of physical activity performed for $30 \mathrm{~min}$ at least three times a week outside of work (11).

\section{CYP2A6 genotyping}

Blood was collected from 1344 subjects, DNA was extracted, and samples were genotyped for CYP $2 A 6$ alleles as described in detail in our previous paper (12). Normal, intermediate, slow, and poor CYP2A6 metabolizers are defined here based on the predicted pharmacokinetic impact of genotypes resulting from the different variant alleles studied $(7,13)$. The CYP $2 A 6^{*} 9$ allele was considered a 'decrease of function' allele (D) and *4, *5, *7, and *10 were considered 'lossof-function' (L) alleles (12). 'Normal metabolizers' were defined as having neither a D nor an L allele (i.e. ${ }^{*} 1 /{ }^{*} 1$ ). 'Intermediate metabolizers' had only one D allele (e.g. *1/*9). 'Slow metabolizers' had either one L allele or two D alleles (e.g. $* 1 / * 4$ or $* 9 / * 9)$ and 'poor metabolizers' had either one L and one D allele or two L alleles (e.g. $* 9 / * 4$, or $* 4 / * 4)(7,13)$.

\section{Measurement of abdominal obesity}

Waist-to-hip ratio (WHR) was calculated by dividing the waist circumference by the hip circumference. Abdominal obesity was defined by WHR $\geq 0.90$ for male and $\geq 0.85$ for female (14).

\section{Measurement of insulin resistance and insulin secretion}

Overnight fasting serum glucose (FSG) levels were tested as described before (8). Fasting serum insulin (FSI) was measured by iodine $\left[{ }^{125} \mathrm{I}\right]$-insulin RIA. Indices of insulin resistance ( $\left.\mathrm{R}^{\prime}\right)$ and insulin secretion $\left(\beta^{\prime}\right)$ were obtained by the modified homeostasis model assessment (HOMA') approach as described by Jenkins et al. (15). HOMA- $\beta$ ' $=$ $(\mathrm{Ln}(\mathrm{FSI})-\mathrm{c}) / \mathrm{FSG}$ and HOMA-R' $=(\mathrm{Ln}(\mathrm{FSI})-\mathrm{c}) \times \mathrm{FSG}$ where $c$ equals 1.322 .

\section{Measurement of serum cotinine concentration}

Serum cotinine concentration was measured by ELISA kit with a sensitivity of $1 \mathrm{ng} / \mathrm{ml}$. Lower serum cotinine, for any given level of smoking (6), was assumed to 
reflect higher levels of nicotine in the body and was thus used as an inverse proxy of serum nicotine levels.

\section{Diagnostic criteria for T2DM}

T2DM was defined as a self-reported history of T2DM (confirmed by the use of insulin or oral hypoglycemic agents) plus newly diagnosed T2DM using WHO diagnostic criteria for diabetes (fasting glucose $\geq 7.0 \mathrm{mmol} / \mathrm{l}$ or $2 \mathrm{~h}$ postprandial glucose $\geq 11.1 \mathrm{mmol} / \mathrm{l})(8)$.

\section{Statistical analysis}

A series of chi-square tests were employed to analyze the homogeneity between T2DM $(n=154)$ and nondiabetics $(n=1286)$ and the distribution of lifestyles among light $(n=670)$, moderate $(n=629)$, and heavy smokers $(n=141)$. If conditions for chi-square test were not satisfied, Fisher's exact test was used.

A multivariate logistic regression was conducted with $\mathrm{T} 2 \mathrm{DM}(0=$ no, $1=$ yes $)$ as the independent variable and smoking quantity $(1=$ light, $2=$ moderate, $3=$ heavy smoker) and CYP2A6 genotypes $(1=$ normal, $2=$ intermediate, $3=$ slow, $4=$ poor metabolizers) as independent variables, controlling for age, education, gender, and family diabetic history. Smoking quantity and CYP2A6 genotypes were entered into the model and a product term was added between smoking quantity and CYP2A6 genotypes for testing CYP $2 A 6$ by smoking quantity interactions.

A structural equation model was used to examine the relationship between smoking quantity, CYP2A6 genotypes, abdominal obesity $(0$, normal and 1 , abdominal obesity), insulin resistance $(0 \leq$ median and $1>$ median $)$, insulin secretion $(0 \leq$ median and $1>$ median), and T2DM. Standardized path coefficients and the significance of the direct and indirect effects are presented. The path graph (Fig. 2) shows the arrows that represent significant $(P \leq 0.05)$ results. In conducting path-modeling analysis, satisfactory model fit was indicated by root mean square error of approximation (RMSEA) $\leq 0.10$ (16) and by goodness of fit index (GFI), incremental fit index (IFI), and comparative fit index (CFI) $\geq 0.90$ (17).

The statistical power to detect the distribution of T2DM between different smoking quantity groups was calculated using the equation

$$
z_{\beta}=\frac{\left|\pi_{1}-\pi_{2}\right|-z_{\alpha} \sqrt{\pi(1-\pi)\left(\frac{1}{n_{1}}+\frac{1}{n_{2}}\right)}}{\sqrt{\frac{\pi_{1}\left(1-\pi_{1}\right)}{n_{1}}+\frac{\pi_{2}\left(1-\pi_{2}\right)}{n_{2}}}}
$$

where $n_{1}$ and $n_{2}$ were the sizes of the two samples, $\pi_{1}$ and $\pi_{2}$ were the probabilities of association in the two populations respectively. $Z_{\alpha}$ was the critical value of statistical significance. The statistical power was subsequently derived from $Z_{\beta}$.

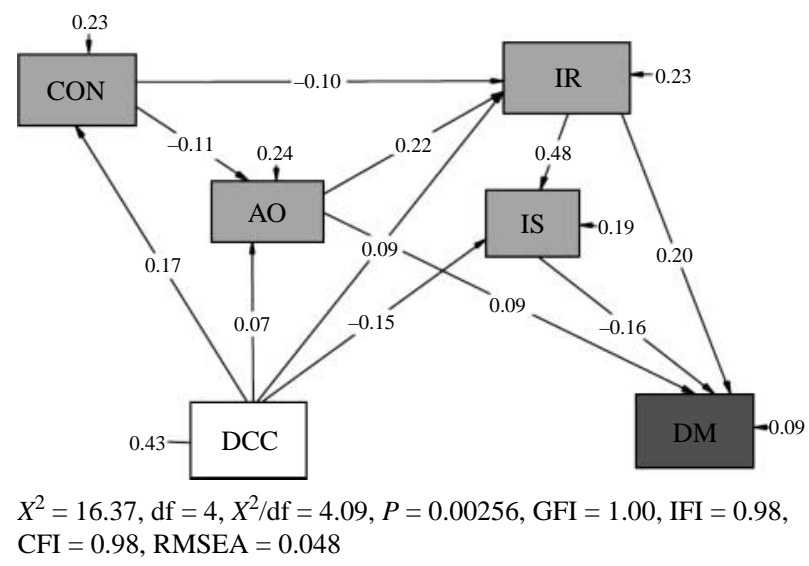

Figure 2 Structural equation model path graph among cigarette smoking, serum cotinine, abdominal obesity, insulin resistance, insulin secretion, and type 2 diabetes. DCC, daily cigarettes consumed $(0=1-9$ cigarettes/day, $1=10-20$ cigarettes/day, $2>20$ cigarettes/day); CON, serum cotinine $(0=$ cotinine $\leq 196.65$, $1=$ cotinine $>196.65) ; \mathrm{AO}$, abdominal obesity $(0=$ no, $1=$ yes $)$; $\mathrm{IR}$, insulin resistance $(0=$ HOMA-IR $\leq 1.68,1=$ HOMA-IR $>1.68)$; IS, insulin secretion ( $0=$ HOMA- $\beta \leq 0.06,1=$ HOMA- $\beta>0.06)$; DM, type 2 diabetes $(0=$ no, $1=$ yes $)$.

The frequencies of CYP $2 A 6^{*} 4, * 5, * 7, * 9$, and $* 10$ alleles were in Hardy-Weinberg equilibrium $(P>0.05)$. All $P$ values were two sided, and statistical significance was $P=0.05$. Except for the structural equation model fitted with LISREL870 (SSI, Inc., Lincolnwood, IL, USA), all analyses were conducted with SPSS 13.0 (SPSS, Inc., Chicago, IL USA).

\section{Results}

\section{Characteristics of smokers}

The mean age of the smokers $(n=1334)$ was 54.6 (s.D. $=11.9$ ) years old with the range from 20 to 85 . The majority of smokers $(92.4 \%)$ were males. There were statistically significant distributions of age, family history of diabetes, and abdominal obesity between smokers with and without T2DM. Other demographic characteristics are shown in Table 1.

\section{Interaction of smoking quantity and CYP2A6 genotypes on T2DM}

Heavy smokers had a higher risk of T2DM than the light smokers (adjusted odds ratio (OR): 1.75; 95\% $\mathrm{CI}=1.01-3.05)$, but the main effects of moderate smoking and CYP2A6 genotypes on T2DM were not significant. The interactions between smoking quantity and CYP2A6 genotype were statistically significant such that heavy smokers with either slow or poor metabolizer genotypes were more likely to have T2DM than normal metabolizers (ORs: $5.12(95 \% \mathrm{CI}=1.08-24.23)$; $8.54(95 \% \mathrm{CI}=1.28-57.02)$ respectively; Table 2$)$. 
Table 1 The general characteristics of 1344 Chinese smokers stratified by type 2 diabetes (T2DM). Data are presented as $n(\%)$.

\begin{tabular}{|c|c|c|c|c|}
\hline General characteristics & $\begin{array}{l}\text { Controls } \\
(n=1197)\end{array}$ & $\begin{array}{c}\text { T2DM } \\
(n=147)\end{array}$ & $\chi^{2}$ & $P$ value \\
\hline $\begin{array}{l}\text { Age (years) } \\
<30 \\
\sim 30 \\
\sim 40 \\
\sim 50 \\
\sim 60 \\
\sim 70\end{array}$ & $\begin{array}{c}47(3.9) \\
116(9.7) \\
259(21.6) \\
401(33.5) \\
301(25.2) \\
73(6.1)\end{array}$ & $\begin{aligned} 0 & (0.00) \\
4 & (2.7) \\
27 & (18.4) \\
41 & (27.9) \\
51 & (34.7) \\
24 & (16.3)\end{aligned}$ & 38.34 & $<0.001$ \\
\hline $\begin{array}{l}\text { Gender } \\
\text { Male } \\
\text { Female }\end{array}$ & $\begin{array}{c}1112(92.9) \\
85(7.1)\end{array}$ & $\begin{array}{r}130(88.4) \\
17(11.6)\end{array}$ & 3.72 & 0.054 \\
\hline $\begin{array}{l}\text { Education } \\
\text { School } \\
\text { Elementary or lower } \\
\text { Junior middle } \\
\text { Senior middle or VS } \\
\text { College or above }\end{array}$ & $\begin{array}{l}246(20.6) \\
405(33.7) \\
379(31.7) \\
167(14.0)\end{array}$ & $\begin{array}{l}37(25.2) \\
45(30.6) \\
43(29.3) \\
22(14.9)\end{array}$ & 2.07 & 0.558 \\
\hline $\begin{array}{l}\text { Family history of diabetes } \\
\text { No } \\
\text { Yes }\end{array}$ & $\begin{array}{r}1038(86.7) \\
159(13.3)\end{array}$ & $\begin{array}{r}112(76.2) \\
35(23.8)\end{array}$ & 11.75 & 0.001 \\
\hline $\begin{array}{l}\text { Alcohol consumption } \\
\text { No } \\
\text { Yes } \\
\text { Former drinker }\end{array}$ & $\begin{array}{l}791(66.1) \\
332(27.7) \\
74(6.2)\end{array}$ & $\begin{array}{l}97(66.0) \\
37(25.2) \\
13(8.8)\end{array}$ & 1.75 & 0.418 \\
\hline $\begin{array}{l}\text { Physical exercise } \\
\text { No } \\
\text { Yes }\end{array}$ & $\begin{array}{l}270(22.6) \\
927(77.4)\end{array}$ & $\begin{array}{r}37(25.2) \\
110(74.8)\end{array}$ & 0.51 & 0.476 \\
\hline $\begin{array}{l}\text { Abdominal obesity } \\
\text { No } \\
\text { Yes }\end{array}$ & $\begin{array}{l}747(62.4) \\
450(37.6)\end{array}$ & $\begin{array}{l}49(33.3) \\
98(66.7)\end{array}$ & 45.8 & $<0.001$ \\
\hline $\begin{array}{l}\text { CYP2A6 genotype (metabolizers) } \\
\text { Normal } \\
\text { Intermediate } \\
\text { Slow } \\
\text { Poor }\end{array}$ & $\begin{array}{l}577(48.2) \\
189(15.8) \\
293(24.5) \\
138(11.5)\end{array}$ & $\begin{array}{l}79(53.7) \\
17(11.6) \\
35(23.8) \\
16(10.9)\end{array}$ & 2.42 & 0.490 \\
\hline
\end{tabular}

VS, vocational secondary.

\section{Possible pathways for smoking quantity leading to T2DM}

A one-pathway model fit the data well $(\mathrm{GFI}=1.00, \mathrm{CFI}=$ 0.98 , IFI $=0.98$, and RMSEA $=0.048$ ). The coefficients in the path diagrams indicate that greater smoking quantity might increase the risk of T2DM indirectly (Fig. 2). Daily cigarette smoking was associated with cotinine levels, abdominal obesity, insulin resistance, and insulin secretion. Abdominal obesity altered insulin resistance, which in turn affected insulin secretion. Abdominal obesity, insulin resistance, and insulin secretion had direct effects on T2DM.

\section{Discussion}

\section{The interaction between smoking and CYP2A6 genotypes on T2DM}

Associations between smoking and CYP2A6 genotypes have been observed for the development of lung cancer (18), pancreatic cancer (19), and head and neck cancer (20). Here, we identify an interaction between smoking quantity and CYP2A6 genotypes on T2DM, after controlling for age, gender, education, and family history of diabetes. Compared with the light smokers with normal CYP2A6 metabolizer genotypes and other groups of smokers, heavy smokers with slow and poor metabolizer genotypes had a significant increased risk of T2DM. There are at least two potentially plausible biological mechanisms underlying this observed interaction.

The first potential mechanism is that heavy smokers with slow and poor metabolizer genotypes may be at higher risk of T2DM compared with the light smokers with normal metabolizer genotypes due to the pancreas exposed to greater circulating levels of nicotine. Many experimental and clinical studies have reported associations between nicotine and decreased insulin sensitivity and insulin secretion, which may contribute to apoptosis of islet $\beta$-cells; these results suggested that nicotine was responsible for the association between smoking quantity and development of diabetes (21). About $80 \%$ of inhaled nicotine is metabolically inactivated by the CYP2A6 enzyme into cotinine; cotinine is further metabolized into trans-3-hydroxycotinine by the same enzyme and all three compounds are 
Table 2 The interaction effect between daily cigarette consumption and CYP2A6 genotypes on T2DM ${ }^{\mathrm{a}}$ in 1344 smokers.

\begin{tabular}{|c|c|c|c|c|c|}
\hline & $\begin{array}{c}\text { Controls } \\
(n=1197) \\
n(\%)\end{array}$ & $\begin{array}{c}\text { Cases } \\
(n=147) \\
n(\%)\end{array}$ & $\begin{array}{c}\text { Model 1 } \\
\text { AOR }^{\mathrm{b}}(95 \% \mathrm{Cl})\end{array}$ & $\begin{array}{c}\text { Model } 2 \\
\text { AOR }^{\mathrm{b}}(95 \% \mathrm{Cl})\end{array}$ & $\boldsymbol{P}$ value $^{\dagger}$ \\
\hline \multicolumn{6}{|l|}{ Daily cigarette consumption } \\
\hline $1-10$ & $552(46.1)$ & $58(39.5)$ & 1 & 1 & \\
\hline $11-20$ & 529 (44.2) & $68(46.2)$ & $1.25(0.86-1.84)$ & $1.18(0.70-1.98)$ & \\
\hline$>20$ & $116(9.7)$ & $21(14.3)$ & $1.75^{\star}(1.01-3.05)$ & $0.87(0.38-2.01)$ & \\
\hline \multicolumn{6}{|l|}{ CYP2A6 genotype } \\
\hline Normal met & 577 (48.2) & $79(53.7)$ & 1 & 1 & \\
\hline Intermediate met & 189 (15.8) & $17(11.6)$ & $0.66(0.38-1.16)$ & $0.51(0.21-1.28)$ & \\
\hline Slow met & $293(24.5)$ & $35(23.8)$ & $0.92(0.60-1.41)$ & $0.79(0.40-1.58)$ & \\
\hline Poor met & $138(11.5)$ & $16(10.9)$ & $0.96(0.54-1.72)$ & $0.63(0.25-1.61)$ & \\
\hline \multicolumn{6}{|l|}{ Interaction effect } \\
\hline Intermediate met $\times(11-20 \mathrm{cig} /$ day $)$ & & & & $0.93(0.26-3.40)$ & 0.914 \\
\hline Intermediate met $\times(>20$ cig $/$ day $)$ & & & & $2.44(0.59-10.09)$ & 0.219 \\
\hline Slow met $\times(11-20 \mathrm{cig} /$ day $)$ & & & & $1.09(0.43-2.78)$ & 0.850 \\
\hline Slow met $\times(>20$ cig/day $)$ & & & & $5.12^{*}(1.08-24.23)$ & 0.040 \\
\hline Poor met $\times(11-20$ cig/day $)$ & & & & $1.39(0.39-5.02)$ & 0.610 \\
\hline Poor met $\times(>20 \mathrm{cig} / \mathrm{day})$ & & & & $8.54^{*}(1.28-57.02)$ & 0.027 \\
\hline
\end{tabular}

AOR, adjusted odds ration; cig, cigarettes; met, metabolizers. ${ }^{\star} P<0.05,{ }^{\dagger} P$ for interaction test.

${ }^{a}$ Dependent variable: type 2 diabetes $(0=$ no, $1=$ yes).

${ }^{b}$ Binary logistic regression model adjusted for age, gender, education, and family history of diabetes.

excreted in urine (22). CYP2A6 genetic polymorphisms moderate the rates and extent of CYP2A6-mediated inactivation of nicotine (22). Therefore, smokers possessing CYP2A6 slow or poor metabolizer genotypes, who smoke more than 20 cigarettes per day, are more likely to saturate this inactivation pathway, thereby accumulating higher nicotine plasma levels. Given the apparent consequences of increased plasma nicotine on insulin secretion, insulin resistance, and abdominal obesity, persistently elevated levels of nicotine, might logically increase the risk of developing T2DM.

Another potential mechanism underlying the difference in risk for T2DM between heavy and light smokers with differing CYP2A6 genotypes may be via nicotine-induced pancreatic islet cell cytotoxicity. Chemicals in tobacco smoke other than nicotine, such as 4-(methylnitrosamino)1-(3-pyridyl)-1-butanone (NNK), can be metabolically activated to carcinogens by CYP2A6 in liver or CYP2E1 expressed in pancreatic islets (23). In smokers with CYP2A6 slow or poor metabolizing genotype, the hepatic first-pass clearance of tobacco nitrosamines may be reduced resulting in higher systemic levels of these precarcinogens and greater exposure of other organs, such as pancreas (24). The higher levels of nitrosamines in pancreatic islet cells could lead to metabolic activation by cytochrome P450 enzymes (CYPs), including CYP2E1; this increased exposure to nicotine and/or nitrosamines could lead to pancreatic inflammation and apoptosis of insulin-secreting cells (25), which in turn may reduce insulin secretion and the increased risk of incident T2DM.

\section{Possible pathways for heavy smoking inducing T2DM}

Several hypotheses have been proposed to link smoking quantity and incidence of T2DM $(2,3)$. First, smoking may lead to inadequate compensatory insulin secretion response and insulin resistance. Secondly, inhaled cigarette smoke may be directly toxic to pancreas, which in turn could result in decreased insulin secretion. Thirdly, smoking is associated with other behaviors such as physical inactivity, poor fruit and vegetable intake, and alcohol intake, all of which may contribute to visceral fat accumulation and T2DM.

Abdominal obesity, insulin resistance, insulin secretion, and T2DM are regarded as conditions that may have a common etiological background and strong, inter-related putative pathophysiology (5). However, not all obese and insulin-resistant individuals develop hyperglycemia, because pancreatic $\beta$-cells may increase insulin release sufficiently to overcome the reduced efficiency of insulin action under normal conditions (5). It is only when $\beta$-cell function is unable to compensate adequately for decreased insulin sensitivity that obesity and insulin resistance would ultimately progress to T2DM (26). The results of this study raise a novel, potential theoretical mechanism for the development of T2DM in smokers. In the pathway modeling incorporating cigarette smoking, serum cotinine, abdominal obesity, insulin resistance, insulin secretion, and T2DM, daily cigarette consumption was significantly positively associated with abdominal obesity and insulin resistance, and abdominal obesity and insulin resistance were further significantly positively associated with T2DM. Interestingly, insulin resistance was positively correlated with insulin secretion, while insulin secretion was negatively related to T2DM. These data provide additional evidence that cigarette smoking may contribute to the accumulation of visceral fat and risk of insulin resistance. These results are consistent with at least two previous studies that also observed that cigarette smokers had greater WHR 
compared with nonsmokers $(27,28)$ and that there was a dose-response relationship between WHR and amount of cigarettes smoked $(27,28)$. Several crosssectional surveys have demonstrated that nondiabetic chronic smokers had higher insulin resistance and hyperinsulinemia compared with nonsmokers (3) and at least one study reported lower $\beta$-cell function among normoglycemic smokers (29) while another study observed high $\beta$-cell values in current smokers and low $\beta$-cell values in former smokers compared with nonsmokers (30). Taken together, these results support the first-pathway hypothesis that smoking may lead to inadequate compensatory insulin secretion response and insulin resistance, for a causative relationship between smoking and T2DM.

There is some evidence that cigarette smoking could acutely impair insulin action in normal subjects and T2DM patients $(31,32)$ and clinical studies have shown that direct negative effects of smoking on $\beta$-cells (21). Similarly, this study revealed that daily cigarette consumption was positively associated with insulin secretion and the latter was negatively related to T2DM. These findings suggest that the decrease in insulin secretion induced by smoking might play a contributing role in the association between smoking and T2DM, consistent with our second hypothesis that inhaled cigarette smoke may be directly toxic to the pancreas, which in turn could result in decreased insulin secretion.

Finally, this study also found that heavy smokers had a higher clustering of unhealthy behaviors, including drinking alcohol, eating less fruit, and taking less physical exercise as well as having a higher proportion of abdominal obesity compared with lighter smokers (see Supplementary Table 1, see section on supplementary data given at the end of this article), consistent with our third hypothesis that smoking is associated with other behaviors that may contribute to visceral fat accumulation and T2DM.

\section{Limitations}

As with any cross-sectional study, causal relationships cannot be established but must be inferred and interpreted in the context of biological plausibility, an evidence of a dose-effect relationship and other supporting data. Secondly, this study included several sub-divisions of subjects and subsequent analyses. Therefore, some of our results may be false positive, having arisen by chance. Therefore, associations of borderline statistical significance should be interpreted with caution and a prospective study is needed to confirm these results. However, the lowest and highest statistical power of testing the association of smoking quantity (three groups) and T2DM was 91.3 and $>99.0 \%$ in this study. Thirdly, diabetes medications, such as use of insulin or oral hypoglycemic agents, were not assessed, which might have affected the measurement of insulin resistance and insulin secretion. Fourth, not all CYP2A6 genetic variants were assayed in this study. Therefore, some misclassification of people with untested variant CYP2A6 genotypes may be grouped as normal metabolizers. Fifth, participants' dietary and drug histories were not investigated, which might affect the activity of CYP2A6 (6) and could further confound the relationship of CYP2A6 genotypes with T2DM. Sixth, we did not include additional smoking phenotypes such as puff volume or smoking duration that might contribute to the association between cigarette smoking and insulin secretion and T2DM (30). Finally, endothelial dysfunction could provide an alternative explanation of the relationship between nicotine exposure and T2DM. However, endothelial function was not assessed in this study.

\section{Conclusions}

In summary, quantity of cigarettes smoked interacts with CYP2A6 genotype to increase risk of T2DM, and we observed that the relationship between cigarette smoking and T2DM was mediated by serum cotinine, abdominal obesity, insulin resistance, and insulin secretion. These findings extend our understanding of the possible effects of cigarette smoking on T2DM and may have important public health implications for tobacco control and diabetes prevention.

\section{Supplementary data}

This is linked to the online version of the paper at http://dx.doi.org/10. 1530/EJE-11-0596.

\section{Declaration of interest}

Dr R F Tyndale holds shares in Nicogen, a company focused on the development of novel smoking cessation treatments. No support was provided by Nicogen for this study and the manuscript was not reviewed by other members of the company. Dr R F Tyndale has also consulted for Novartis on tobacco cessation. All other authors have no conflicts of interests to declare in relation to this report.

\section{Funding}

This study was funded by the Guangzhou Health Bureau (2005Zda-001) and the National Institute on Drug Abuse/National Institutes of Health grants K08-014276 and R21-027331.

We acknowledge the financial support from the Centre for Addiction and Mental Health (R F Tyndale, Q Zhou) and Canadian Institutes for Health Research MOP86471. R F Tyndale holds a Canada Research Chair in Pharmacogenetics.

\section{Acknowledgements}

This study was completed with the assistance of the following units: Disease Prevention and Control Center of Haizhu District and Baiyun District, the Health Inspection Institute of Huangpu District, the Sixth Affiliated Hospital of Sun Yat-sen University, and the Health Care Center of Huayin Community, Jinyang Community, Longteng Community, and the Department of Health Education of Liwan Hospital. 


\section{References}

1 Cho NH, Chan JC, Jang HC, Lim S, Kim HL \& Choi SH. Cigarette smoking is an independent risk factor for type 2 diabetes: a fouryear community-based prospective study. Clinical Endocrinology 200971 679-685. (doi:10.1111/j.1365-2265.2009.03586.x)

2 Willi C, Bodenmann P, Ghali WA, Faris PD \& Cornuz J. Active smoking and the risk of type 2 diabetes: a systematic review and meta-analysis. Journal of the American Medical Association 2007 298 2654-2664. (doi:10.1001/jama.298.22.2654)

3 Chiolero A, Faeh D, Paccaud F \& Cornuz J. Consequences of smoking for body weight, body fat distribution, and insulin resistance. American Journal of Clinical Nutrition $2008 \mathbf{8 7}$ 801-809.

4 Persson PG, Carlsson S, Svanstrom L, Ostenson CG, Efendic S \& Grill V. Cigarette smoking, oral moist snuff use and glucose intolerance. Journal of Internal Medicine $2000 \mathbf{2 4 8} 103-110$. (doi:10.1046/j.1365-2796.2000.00708.x)

5 Kahn SE, Hull RL \& Utzschneider KM. Mechanisms linking obesity to insulin resistance and type 2 diabetes. Nature 2006 444 840-846. (doi:10.1038/nature05482)

6 Hukkanen J, Jacob P III \& Benowitz NL. Metabolism and disposition kinetics of nicotine. Pharmacological Reviews 200557 79-115. (doi:10.1124/pr.57.1.3)

7 Schoedel KA, Hoffmann EB, Rao Y, Sellers EM \& Tyndale RF. Ethnic variation in CYP2A6 and association of genetically slow nicotine metabolism and smoking in adult Caucasians. Pharmacogenetics 200414 615-626. (doi:10.1097/00008571-20040900000006)

8 Wang H, Qiu Q, Tan LL, Liu T, Deng XQ, Chen YM, Chen W, Yu XQ, $\mathrm{Hu} \mathrm{BJ} \&$ Chen WQ. Prevalence and determinants of diabetes and impaired fasting glucose among urban community-dwelling adults in Guangzhou, China. Diabetes $\mathcal{E}$ Metabolism 200935 378-384. (doi:10.1016/j.diabet.2009.03.006)

9 Centers for Disease Control. National Health Interview Survey: Early release of selected estimates based on data from January to September 2007, www.cdc.gov. Accessed 20 February 2011, 2007

10 Wen W, Xiang YB, Zheng W, Xu WH, Yang G, Li H \& Shu XO. The association of alcohol, tea, and other modifiable lifestyle factors with myocardial infarction and stroke in Chinese men. CVD Prevention and Control 20083 133-140. (doi:10.1016/j.cvdpc. 2008.07.001)

11 Park MS, Chung SY, Chang Y \& Kim K. Physical activity and physical fitness as predictors of all-cause mortality in Korean men. Journal of Korean Medical Science 200924 13-19. (doi:10.3346/ jkms.2009.24.1.13)

12 Liu T, David SP, Tyndale RF, Wang H, Zhou Q, Ding P, He YH, Yu XQ, Chen W, Crump C, Wen XZ \& Chen WQ. Associations of CYP2A6 genotype with smoking behaviors in Southern China. Addiction 2011105 985-994. (doi:10.1111/j.1360-0443.2010. 03353.x)

13 Mwenifumbo JC \& Tyndale RF. Genetic variability in CYP2A6 and the pharmacokinetics of nicotine. Pharmacogenomics $2007 \mathbf{8}$ 1385-1402. (doi:10.2217/14622416.8.10.1385)

14 Adamu G Bakari \& Onyemelukwe GC. Indices of obesity among type-2 diabetic Hausa-Fulani Nigerians. International Journal of Diabetes $\mathcal{E}$ Metabolism $20051328-29$.

15 Jenkins AB, Samaras K, Carey DG, Kelly P \& Campbell LV. Improved indices of insulin resistance and insulin secretion for use in genetic and population studies of type 2 diabetes mellitus. Twin Research 2000 3 148-151. (doi:10.1375/13690520032 0565427)

16 Kline RB. Principles and Practice of Structural Equation Modeling. New York: The Guilford Press, 1998.

17 Bentler PM. On the fit of models to covariances and methodology to the Bulletin. Psychological Bulletin 1992112 400-404. (doi:10. 1037/0033-2909.112.3.400)

18 Fujieda M, Yamazaki H, Saito T, Kiyotani K, Gyamfi MA, Sakurai M, Dosaka-Akita H, Sawamura Y, Yokota J, Kunitoh H \&
Kamataki T. Evaluation of CYP2A6 genetic polymorphisms as determinants of smoking behavior and tobacco-related lung cancer risk in male Japanese smokers. Carcinogenesis 200425 2451-2458. (doi:10.1093/carcin/bgh258)

19 Kadlubar S, Anderson JP, Sweeney C, Gross MD, Lang NP, Kadlubar FF \& Anderson KE. Phenotypic CYP2A6 variation and the risk of pancreatic cancer. Journal of the Pancreas 200910 263270.

20 Ruwali M, Pant MC, Shah PP, Mishra BN \& Parmar D. Polymorphism in cytochrome $\mathrm{P} 450$ 2A6 and glutathione $S$-transferase P1 modifies head and neck cancer risk and treatment outcome. Mutation Research 2009669 36-41. (doi:10.1016/j.mrfmmm.2009.04.007)

21 Xie XT, Liu Q, Wu J \& Wakui M. Impact of cigarette smoking in type 2 diabetes development. Acta Pharmacologica Sinica 200930 784-787. (doi:10.1038/aps.2009.49)

22 Rossini A, de Almeida Simao T, Albano RM \& Pinto LF. CYP2A6 polymorphisms and risk for tobacco-related cancers. Pharmacogenomics 20089 1737-1752. (doi:10.2217/14622416.9.11. 1737)

23 Kamataki T, Nunoya K, Sakai Y, Kushida H \& Fujita K. Genetic polymorphism of CYP2A6 in relation to cancer. Mutation Research 1999428 125-130. (doi:10.1016/S1383-5742(99)00040-X)

24 Tan W, Chen GF, Xing DY, Song CY, Kadlubar FF \& Lin DX. Frequency of CYP2A6 gene deletion and its relation to risk of lung and esophageal cancer in the Chinese population. International Journal of Cancer 200195 96-101. (doi:10.1002/10970215(20010320)95:2<96::AID-IJC1017> 3.0.CO;2-2)

25 Lees Murdock DJ, Barnett YA \& Barnett CR. DNA damage and cytotoxicity in pancreatic beta-cells expressing human CYP2E1. Biochemical Pharmacology 200468 523-530. (doi:10.1016/j.bcp. 2004.04.008)

26 Kriketos AD, Carey DG, Jenkins AB, Chisholm DJ, Furler SM \& Campbell LV. Central fat predicts deterioration of insulin secretion index and fasting glycaemia: 6-year follow-up of subjects at varying risk of type 2 diabetes mellitus. Diabetic Medicine 200320 294-300. (doi:10.1046/j.1464-5491.2003.00938.x)

27 Shimokata H, Muller DC \& Andres R. Studies in the distribution of body fat. III. Effects of cigarette smoking. Journal of the American Medical Association 1989261 1169-1173. (doi:10.1001/jama. 261.8.1169)

28 Canoy D, Wareham N, Luben R, Welch A, Bingham S, Day N \& Khaw KT. Cigarette smoking and fat distribution in 21828 British men and women: a population-based study. Obesity Research 2005 13 1466-1475. (doi:10.1038/oby.2005.177)

29 Ostgren CJ, Lindblad U, Ranstam J, Melander A \& Rastam L. Associations between smoking and beta-cell function in a nonhypertensive and non-diabetic population. Skaraborg Hypertension and Diabetes Project. Diabetic Medicine 200017 445-450. (doi:10.1046/j.1464-5491.2000.00294.x)

30 Daniel M \& Cargo MD. Association between smoking, insulin resistance and beta-cell function in a North-Western First Nation. Diabetic Medicine 200421 188-193. (doi:10.1046/j.1464-5491. 2003.01064.x)

31 Attvall S, Fowelin J, Lager I, Von Schenck H \& Smith U. Smoking induces insulin resistance - a potential link with the insulin resistance syndrome. Journal of Internal Medicine 1993233 327-332. (doi:10.1111/j.1365-2796.1993.tb00680.x)

32 Epifano L, Di Vincenzo A, Fanelli C, Porcellati F, Perriello G, De Feo P, Motolese M, Brunetti P \& Bolli GB. Effect of cigarette smoking and of a transdermal nicotine delivery system on glucoregulation in type 2 diabetes mellitus. European Journal of Clinical Pharmacology $1992 \mathbf{4 3}$ 257-263. (doi:10.1007/ BF02333019)

Received 19 May 2011

Revised version received 14 September 2011

Accepted 28 September 2011 